\title{
The effect of the American Society of Anesthesiology classification scores on complications associated with percutaneous nephrolithotomy
}

\author{
Erdem Kisa $^{1}$, Cem Yücel ${ }^{1}$, Salih Budak ${ }^{2}$, Murat Ucar ${ }^{1}$, Mehmet Zeynel Keskin ${ }^{1}$, Ozgur Cakmak ${ }^{1}$, \\ Gokhan Koc ${ }^{1}$, Zafer Kozacioglu ${ }^{1}$ \\ ${ }^{1}$ Tepecik Training and Research Hospital, Turkey; \\ 2 Sakarya Training and Research Hospital, Turkey.
}

\begin{abstract}
Summary Objectives: We aimed to evaluate the effect of American Society of Anesthesiology (ASA) classification scoring and age on complications and surgical outcomes during and after percutaneous nephrolithotomy (PCNL) operation.

Material and methods: The records of 263 patients, above the age of 18 years, that underwent PCNL surgery between October 2014 and May 2017 were evaluated retrospectively. The patients were divided into three groups based on their ASA risk scores (ASA 1,2,3) and into two groups based on their age (younger and older than 65 years). Postoperative complications were assessed according to the ASA groups and age and according to the Clavien classification system.

Results: The number of patients in the ASA 1, 2, and 3 groups were 97 (36.8\%), 131 (49.8\%) and 35 (13.3\%), respectively. Four patients in ASA4 were not included in the study. There was no significant difference in ASA 1, 2, 3 groups in terms of changes in $\mathrm{Hgb}$ values, mean duration of operation, and mean hospital stay. When ASA1 was compared to ASA3 and ASA2 was compared to ASA3, there was no significant difference in the incidence of all complication rates.

There were $159(60.4 \%)$ patients in the young group and 104 (39.5\%) patients in the elderly group. Postoperative PCNL complications of these 2 groups were compared according to Clavien classification system and no significant difference was found in incidence of complications.

Conclusions: We believe that PCNL operation can be performed effectively and safely in both ASA3 patients and patients above the age of 65 years.
\end{abstract}

KEY WORDS: American Society of Anesthesiologists' scoring system; Clavien classification system; Percutaneous nephrolithotomy; Surgical complications; Geriatric.

Submitted 25 March 2018; Accepted 29 April 2018

\section{INTRODUCTION}

Nephrolithiasis is one of the most common diseases, affecting nearly one in thirteen women and one in seven men (1). Certain factors such as location and composition of the stone, patients' anatomy and comorbidities play an important role in the choice of treatment in urinary system stone disease. Stone size is the most important factor in choosing the surgical modality for the removal of the stone. Percutaneous nephrolithotomy
(PCNL) is a standard operation in following cases: staghorn stones larger than $20 \mathrm{~mm}$, stones resistant to shock wave lithotripsy (SWL), cystine stones, patients with anatomically anomalous upper urinary system, patients with anatomical defects (scoliosis, kyphosis or spasticity), lower pole stones larger than $15 \mathrm{~mm}$ and stones in transplant kidneys $(2,3)$. The reliability, efficacy and complication rates of the PCNL operation in elderly patients have been evaluated in many studies, just like the impact of the American Society of Anesthesiologist (ASA) classification scores (4-10).

The prevalence of systemic diseases increases with aging. The ASA classification is a system in which patients are evaluated according to the risk of anesthesia prior to surgery. This system can be used to choose the type of anesthesia, to determine the monitoring method, and to assess the tolerance of patients to various surgical manipulations such as surgical position. Staying in prone position during PCNL can lead to some difficulties; such as those in controlling the airway, maintaining the vascular access and ventilation of patients with lung diseases in particular $(11,12)$.

In this study, we aimed to compare the effect of ASA risk classification scores on complications during and after PCNL surgery.

\section{Materials AND MEthods}

We retrospectively reviewed the records of 263 patients over the age of 18 years who underwent PCNL surgery in our clinic between October 2014 and May 2017. Patients were divided into three groups: ASA1, ASA2 and ASA3. Patients with an ASA score of 4 were excluded from the study. Patients were also divided into two groups according to their age: elderly (65 years and over) and young (18-65). Local ethics committee approved our study. An expert anesthesiologist evaluated all the patients preoperatively. The risk of surgery was determined according to the ASA classification score (Table 1).

Demographic, surgical and perioperative anesthetic data and postoperative outcomes were obtained from patient records (Table 2 and 3). Patients with sterile urine culture were taken into operation. Patients with urinary 
Table 1.

ASA scoring system.

\begin{tabular}{ll}
\hline ASA-I & A completely healthy patient \\
\hline ASA-II & A patient with mild systemic disease \\
\hline ASA-III & A patient with severe systemic disease that is not incapacitating \\
\hline ASA-IV & A patient with incapacitating disease that is a constant threat to life \\
\hline ASA-V & A moribund patient who is not expected to live for $24 \mathrm{~h}$ with or without surgery
\end{tabular}

Table 2.

The patients' demographic data and stone locations.

\begin{tabular}{|lccc|}
\hline & ASA 1 & ASA 2 & ASA3 \\
\hline Patients, $n(\%)$ & $97(36.9 \%)$ & $131(49.8 \%)$ & $35(13.3 \%)$ \\
\hline Mean age \pm standard deviation & $44.4 \pm 14.8$ & $44(18-75)$ & $59.7 \pm 11.6$ \\
median (min-max) & $65(29-87)$ & $65.8 \pm 8.8$ & $66(50-93)$ \\
\hline Mean stone burden $\left(\mathrm{mm}^{2}\right)$ & $443.9 \pm 364.3$ & $500.2 \pm 438.8$ & $434.6 \pm 311.7$ \\
\pm standard deviation & 322 & 375 & 399 \\
median (min-max) & $(60-2275)$ & $(112-2772)$ & $(126-1880)$ \\
\hline Complex stone, $\mathrm{n}(\%)$ & $54(55.6 \%)$ & $61(46.5 \%)$ & $20(57.1 \%)$ \\
\hline Noncomplex stone, $\mathrm{n}(\%)$ & $43(44.3 \%)$ & $70(53.4 \%)$ & $15(42.8 \%)$ \\
\hline Stone location & & & $n=0$ \\
Superior & $n=8$ & $n=8$ & $n=2$ \\
Middle & $n=13$ & $n=13$ & $n=21$ \\
Inferior & $n=45$ & $n=72$ & $n=12$ \\
\hline Pelvis & $n=31$ & $n=38$ & $1.2(42 / 35)$ \\
\hline Average access number & $1.2(117 / 97)$ & $1.1(152 / 131)$ & \\
\hline
\end{tabular}

complex, while partial or complete staghorn stones and stones located in both renal pelvis and a single calyx were classified as complex stones.

All PCNL operations were performed in prone position and under general anesthesia and fluoroscopy. A single dose of appropriate intravenous antibiotic was used as antimicrobial prophylaxis. A ureteral catheter fixed to the Foley catheter was placed. Tract dilation up to 30-French was achieved with Amplatz dilators and a 30-French plastic Amplatz sheath was introduced. A 26French rigid nephroscope and ultrasonic lithotripter were used in all cases. A 24-French nephrostomy tube was used for drainage when necessary. The complications of the patients in ASA risk groups were classified according to the modified Clavien scoring system (Table 4). Same criteria were used to compare the patients in the age groups (Table 5). All patients underwent noncontrast CT at first month postoperatively and overall stone-free rate was evaluated.

Since the numerical variables in the groups did not show normal distribution, the median (minimummaximum) was used as the descriptive statistic. Moreover, the number (\%) was used as a descriptive statistic for the categorical variables. A nonparametric Kruskal-Wallis test was used to determine whether there is a difference in numerical variables among the groups. The two proportions

$\mathrm{Z}$ Test or the Fisher exact test were used to assess tract infections were treated according to the antibiogram. All patients were assessed by direct urinary system RX-graphy and unenhanced computerized tomography (CT) preoperatively. The locations of the renal stones were identified as upper, middle or lower calyx, and pelvis. The stone size was calculated by multiplying the widest width and height of the stone. In patients with multiple stones in their urinary system, stone sizes were calculated separately and added. Isolated stones in the upper, middle or lower calyces were classified as non-

Table 3.

Study results by groups.

\begin{tabular}{|c|c|c|c|c|}
\hline & ASA 1 & ASA 2 & ASA3 & $\mathbf{P}$ \\
\hline $\begin{array}{l}{ }^{1} \text { Hgb preop-postop } \\
\text { Median (min-max) }\end{array}$ & $1.70(-0.80-8.70)$ & $1.50(-0.40-5.50)$ & $1.50(-0.30-6.10)$ & 0.474 \\
\hline $\begin{array}{l}\text { 1Mean operative time (min) } \\
\text { Mean } \pm \text { standard deviation } \\
\text { Median (min-max) }\end{array}$ & $\begin{array}{l}93.0 \pm 34.2 \\
90(40-230)\end{array}$ & $\begin{array}{l}92.5 \pm 37.3 \\
85(45-210)\end{array}$ & $\begin{array}{c}100.5 \pm 37.5 \\
90(55-225)\end{array}$ & 0.389 \\
\hline $\begin{array}{l}\text { 1Mean hospitalization (days) } \\
\text { Mean } \pm \text { standard deviation } \\
\text { Median (min-max) }\end{array}$ & $\begin{array}{c}2.8 \pm 1.3 \\
2(2-8)\end{array}$ & $\begin{array}{l}3 \pm 1.7 \\
2(2-10)\end{array}$ & $\begin{array}{c}3.0 \pm 1.9 \\
2(2-10)\end{array}$ & 0.674 \\
\hline 2Postop 1-month stone free (\%) & $69(71.1)$ & $89(67.9)$ & $25(71.4)$ & $0.974 \mathrm{ac}, 0.687 \mathrm{bc}$ \\
\hline Complications & & & & \\
\hline${ }^{3}$ Grade1 n (\%) & $5(5.1 \%)$ & $5(3.8)$ & $1(2.8)$ & $0.999 a c, 0.999 b c$ \\
\hline${ }^{3}$ Grade2 n (\%) & $8(8.1 \%)$ & $16(12.1 \%)$ & $5(14.2 \%)$ & $0.356 \mathrm{ac}, 0.752 \mathrm{bc}$ \\
\hline${ }^{3}$ Grade3 n (\%) & $3(3.0 \%)$ & $6(4.5 \%)$ & $2(5.7 \%)$ & $0.608 \mathrm{ac}, 0.676 \mathrm{bc}$ \\
\hline${ }^{3}$ Grade4 n (\%) & 0 & $2(1.5 \%)$ & $1(2.8 \%)$ & $0.265 \mathrm{ac}, 0.511 \mathrm{bc}$ \\
\hline${ }^{2}$ Overall complication rates & $16.4 \%$ & $22.1 \%$ & $25.7 \%$ & $0.266 \mathrm{ac}, 0.664 \mathrm{bc}$ \\
\hline
\end{tabular}
the difference between the prevalence percentages of categorical variables within the groups, depending on the assumptions. For all tests, the probability of Type I error was set to $\alpha=0.05$. The R Project 3.2.5 package program was used for all statistical analyses.

\section{RESULTS}

The mean age of the groups, the stone dimensions, the ratio of complex to non-complex stones, the distribution of stone location, and the average number of accesses are shown in Table 2.

The changes in hemoglobin (Hgb) levels before and after the operation, the mean duration of operation, and the mean hospital stay of the groups are shown in Table 3. There was no statistically significant difference between the groups in terms of Hgb change, mean duration of operation and mean hospital stay ( $\mathrm{p}=0.474$, 0.389 and 0.674 , respectively).

The overall stone free rates in patients in the ASA 3 group were compared with those in ASA 2 and ASA 1 groups (Table 3).

The overall stone-free rates of the groups were $71.1 \%$ for ASAl, $67.9 \%$ for ASA2, and $71.4 \%$ for ASA3. The separate comparison 
Table 4.

Modified Clavien classification according to ASA groups.

\begin{tabular}{|c|c|c|c|}
\hline Clavien complication rates & ASA 1 n (\%) & ASA 2 n (\%) & ASA3 n (\%) \\
\hline \multicolumn{4}{|l|}{$\overline{\text { GRADE } 1}$} \\
\hline Fever (over $38.5^{\circ} \mathrm{C}$, requiring antipyretic treatment) & $5(5.1)$ & $5(3.8)$ & $1(2.8)$ \\
\hline \multicolumn{4}{|l|}{ GRADE 2} \\
\hline Blood transfusion & $6(6.1)$ & $13(9.9)$ & $4(11.4)$ \\
\hline \multicolumn{4}{|l|}{ Urinary tract infection requiring additional antibiotics } \\
\hline \multicolumn{4}{|l|}{ GRADE 3a } \\
\hline Double-J stent placement for urine leakage $>24 \mathrm{~h}$ (local anesthesia) & ) $1(1.0)$ & $3(2.2)$ & $1(2.8)$ \\
\hline Pleural effusion & 0 & $1(0.7)$ & 0 \\
\hline Pneumothorax & 0 & $1(0.7)$ & 0 \\
\hline \multicolumn{4}{|l|}{ GRADE 3b } \\
\hline \multicolumn{4}{|l|}{ Double-J stent placement for urine leakage $>24 \mathrm{~h}$} \\
\hline AV fistula & & 0 & \\
\hline Perirenal hematoma needing intervention & $1(1.0)$ & 0 & 0 \\
\hline \multirow[t]{2}{*}{ Perioperative bleeding requiring termination of the operation } & 0 & 0 & 0 \\
\hline & 0 & & 0 \\
\hline \multicolumn{4}{|l|}{ GRADE 4a } \\
\hline Pulmonary Emboli (requiring intensive care unit) & 0 & $1(0.7)$ & 0 \\
\hline Neighboring organ injury & 0 & 0 & 0 \\
\hline Nephrectomy & 0 & 0 & 0 \\
\hline Urosepsis & 0 & $1(0.7)$ & $1(2.8)$ \\
\hline \multicolumn{4}{|l|}{ GRADE 5} \\
\hline Death & 0 & 0 & 0 \\
\hline
\end{tabular}

Table 5.

Modified Clavien scoring according to the age groups.

\begin{tabular}{|c|c|c|c|}
\hline Clavien complication & $\begin{array}{c}65 \text { < e elderly } \\
n=104 \\
n(\%)\end{array}$ & $\begin{array}{c}65>\text { young } \\
n=159 \\
n(\%)\end{array}$ & $\mathbf{P}$ \\
\hline GRADE 1 & & & $0.689^{1}$ \\
\hline Fever & $5(4.8)$ & $6(3.8)$ & \\
\hline$\overline{\text { GRADE } 2}$ & & & $0.323^{1}$ \\
\hline Blood transfusion & $12(7.5)$ & $11(10.5)$ & \\
\hline $\begin{array}{l}\text { Urinary tract infection requiring additional antibiotics } \\
\text { (instead of prophylactics) }\end{array}$ & $2(1.2)$ & $4(38)$ & \\
\hline Total & 14 & 15 & \\
\hline GRADE 3a & & & $0.999^{2}$ \\
\hline Double-J stent placement for urine leakage $>24 \mathrm{~h}$ (local anesthesia) & $1(0.6)$ & $1(0.6)$ & \\
\hline Pleural effusion & 0 & $4(3.8)$ & \\
\hline Pneumothorax & $2(1.2)$ & 0 & \\
\hline \multicolumn{4}{|l|}{ GRADE 3b } \\
\hline $\begin{array}{l}\text { Double-J stent placement for urine leakage }>24 \mathrm{~h} \\
\text { (ureter stone, general anesthesia) }\end{array}$ & 0 & $1(0.9)$ & \\
\hline AV fistula & 0 & $1(0.9)$ & \\
\hline Perirenal hematoma needing intervention & 0 & $1(0.9)$ & \\
\hline Perioperative bleeding requiring termination of the operation & 4 & 0 & \\
\hline Total & 0 & 7 & \\
\hline GRADE 4a & & & - \\
\hline Pulmonary Emboli (requiring intensive care unit) & $1(0.6)$ & 0 & \\
\hline Neighboring organ injury & 0 & 0 & \\
\hline Nephrectomy & 0 & 0 & \\
\hline Urosepsis & $1(0.6)$ & 0 & \\
\hline GRADE 5 & & & - \\
\hline Death & 0 & 0 & \\
\hline
\end{tabular}

between ASA3 and ASA1, ASA3 and ASA2 groups at 1-month follow-up did not reveal any statistically significant difference in terms of stone-free percentage ( $p=0.974$ and 0.687 , respectively).

The complications in patients in the ASA 3 group were compared with those in ASA 2 and ASA 1 groups (Table 3). There was no significant difference between ASA1 and ASA3 groups in terms of the separate incidence of grade 1 , grade 2 , grade 3 , and grade 4 complications ( $p=$ $0.999,0.356,0.608,0.265$, respectively). The comparison of ASA2 and ASA3 groups also did not show any significant difference in terms of the separate incidence of grade 1 , grade 2 , grade 3 , and grade 4 complications ( $\mathrm{p}=0.999,0.752,0.676$, and 0.511 respectively). When ASA1 and ASA3, ASA2 and ASA3 groups were compared separately, there was no significant difference in terms of percentage of overall complication rates (Bonferroni correction, $\mathrm{p}=0.266$ and 0.664 , respectively).

There were 104 patients (39.5\%) in the elderly group and 159 patients (60.4\%) in the young group.

The post-PCNL surgery complications of these two groups were compared according to modified Clavien classification system (Table 5). There was no significant difference in the incidence of Grade 1, Grade 2, Grade 3 complications between the age groups ( $>$ $=65$ and < 65) ( $\mathrm{p}=0.689,0.323$, and 0.999 , respectively).

Patients' comorbidities were divided according to the groups.

The mean number of comorbidities in ASA1 was 0.06 (6/97), in ASA2 was $1.2(158 / 131)$, and in ASA3 was 2.1 (75/35). The most commonly observed comorbidity was hypertension (100/263, 38\%).

\section{Discussion}

The PCNL surgery is the standard treatment option for large kidney stones. Many studies have shown that PCNL can be successful in high-risk patients (ASA3 and ASA4) (8-10). An increase in the rate of systemic disease is expected in patients with advanced age. In a study by Kuzgunbay et al. the 
patients who underwent PCNL surgery were divided into two groups based on their age: elderly (65 years and older) and the control group (18-36 years). The comparison of comorbidity prevalence showed that while $73 \%$ of patients in the elderly group had at least one comorbidity, there were no comorbidities in control patients (13). In a study by Nouralizadeh et al. the number of co-morbidities in high-risk patients was 2, while this ratio was 5.4 in a study by Patel et al. (8-10). In our study, we observed that the average number of co-morbidities increased from 0.06 to 2.1 when going from ASAl to ASA3. This increased rate increases the number of medications used by patients, which in turn is an important factor to consider before, during and after the operation by both surgeons and the anesthesiologists, especially in ASA3 patients.

In the literature, the proportion of the elderly individuals among patients undergoing PCNL surgery ranges 10 to $12 \%$ (14). However, in a study by Anagnostou et al., where they set the lower age limit to 70 years, $17 \%$ of the patients undergoing PCNL surgery were in that group (4). In our study, the ratio of elderly patients was 39\%. We believe that our ratio is high because the age limit in our study was 65, our hospital is an institution that receives many referrals, and because the patients who need intensive care after operation were also treated in our hospital.

Bleeding and septic complications of PCNL may become more significant in elderly patients with impaired cardiopulmonary and renal function (15). For this reason, the risks associated with anesthesia may be more prevalent in older patients compared to younger patients.

The anesthesiologists and surgeons are always concerned about invasive treatments such as PCNL when it comes to older patients with renal stones. Therefore, when evaluating treatment alternatives in these patients, general health of the patient should be considered along with the size and location of the stone (16). Careful pre-operative examinations can provide comprehensive safety for surgical procedures in elderly patients (4).

Higher prevalence of complex stones in elderly and highrisk patients can be explained by patients' and surgeons' initial reluctance to do surgery in favor of more conservative treatments and as a result stones get bigger and develop a staghorn formation (10). Sahin et al. reported that stone sizes are larger in elderly patients compared to younger patients (1077.92 $\mathrm{mm}^{2}$ versus $920.85 \mathrm{~mm}^{2}$ ) (5). Similarly, in our study, the median stone size and percentage of complex stone structures were higher in ASA3 patient group.

Although PCNL surgery has been shown to be safe and effective in all age groups, minor and life-threatening complications can occur during and after surgery $(7,17,18)$. PCNL related fever (0-32.1\%), hemorrhage requiring transfusion (0-20\%), embolization (0-1.5\%), urinoma (0$1 \%)$, sepsis $(0.3-1.1 \%)$, thoracic complications (0-1.6\%), organ injury $(0-1.7 \%)$, and death $(0-0.3 \%)$ can be observed at varying rates (19). In 2007, Tefekli et al. developed a modified Clavien classification system for PCNL surgeries in order to better evaluate and inform patients about possible complications. This system also classifies complications seen during and after the operation by grading them (20).
Patel et al. found that the overall risk of complications was higher in the high-risk group compared to the lowrisk group (21.2\% vs. $18.5 \%)$. The majority of complications in the high-risk group consisted of grade 2 complications (12.1\%), while grade 1 complications made up $9.1 \%$. However, there was no significant difference between the complication rates of high-risk group and the low risk group (8). Similarly, the most common complication in our study was grade 2 . When ASAl was compared with ASA3 and ASA2 was compared with ASA3 there was no significant difference in terms of percentage of overall complication rates. Moreover, the comparison of age groups (older and younger than 65 years) also did not show any significant difference in terms of percentage of overall complications.

The studies on bleeding complications during and after PCNL operation in high-risk and elderly patients are controversial. Resorlu et al. have shown that the probability of bleeding increases when comorbidity increases (21). Similarly, Nouralizadeh et al. found that the rate of blood transfusion was higher in in high-risk group compared to the low-risk (ASA1, 2) groups, but Hgb replacement was similar in all groups (10). However, Patel et al. assessed the patients' complications based on the modified Clavien system, and found no difference in terms of bleeding and transfusion requirements between high and low risk groups (8). In the study by Stoller et al. the patients were divided into groups: over and below the age of 65 years. Although both groups had similar preoperative Hgb levels, post-operative blood transfusion rates were higher in elderly group compared to the younger group (26\% to $13.7 \%$ ) (6). In our study, we did not find any differences in Hgb exchange and blood transfusion requirements in both ASA risk groups and in patients younger and older than 65 years. At the same time, there was no difference in terms of Hgb exchange and blood transfusion requirements.

Comorbidities and older age have been shown to affect stone-free rates. Karami et al. reported not seeing any significant difference in stone-free rates between patients younger and older than 65 years (7). Resorlu et al. reported that the increase in the Charlson comorbidity score had significantly reduced the stone-free rates (21).

In the study by Patel et al. the total stone-free rate was $61 \%$ in the high-risk group and $92 \%$ in the low-risk group, and this difference was significant (8). In our study, according to the results of the CT scans on 1month postoperative follow-up there was no significant difference in terms of complete stone-free percentage when we compared ASAl with ASA3 and ASA2 with ASA3 groups ( $p=0.974$ and 0.687 , respectively).

The first limitation of this study is that it was performed retrospectively. Our second limitation is that although the diameter of the access sheath is gradually reduced in PCNL surgeries, we have used 30F sheath in our study. However, since the blood transfusion rates in our study were compatible with the current literature, we decided not to change the sheet diameter.

\section{Conclusions}

With increase in the life expectancy and aging of the world population improving quality of life has become 
very imperative. Aging is associated with increased prevalence of comorbidity and other concomitant risks. We found that although the number of comorbidities and the risk of anesthesia are higher in ASA3 risk group compared with patients in the ASAl and ASA2 risk groups, there was no significant difference in terms of complete stone-free rates, complication rates, and hospitalization times following a PCNL surgery. Therefore, we believe that PCNL surgery can be performed safely and effectively in both high-risk patients with comorbidities as well as elderly patients.

\section{REFERENCES}

1. Stamatelou KK, Francis ME, Jones CA, et al. Time trends in reported prevalence of kidney stones in the United States: 1976 1994. Kidney Int, 2003; 63:1817.

2. Morris DS, Taub DA, Wei JT, et al. Regionalization of percutaneous nephrolithotomy: evidence for the increasing burden of care on tertiary centers. J Urol. 2006; 176:242-246.

3. Srirangam SJ, Darling R, Stopford M, et al. Contemporary practice of percutaneous nephrolithotomy: a review of practice in a single region of the UK. Ann R Coll Surg Engl. 2008; 90:40-44.

4. Anagnostou T, Thompson T, Ng CF, et al. Safety and outcome of percutaneous nephrolithotomy in the elderly: retrospective comparison to a younger patient group.J Endourol. 2008; 22:2139-45.

5. Sahin A, Atsu N, Erdem E, et al. Percutaneous nephrolithotomy in patients aged 60 years or older. J Endourol. 2001; 15:489-491.

6. Stoller ML, Bolton D, St Lezin M, et al. Percutaneous nephrolithotomy in the elderly. Urology. 1994; 44:651-654.

7. Karami H, Mazloomfard MM, Golshan A, et al. Does age affect outcomes of percutaneous nephrolithotomy? Urol J. 2010; 7:17-21.

8. Patel SR, Haleblian GE, Pareek G. Percutaneous nephrolithotomy can be safely performed in the high-risk patient. Urology. 2010, 75:51-55.

9. Toksoz S, Dirim A, Kizilkan Y, et al. The effect of American Society of Anesthesiology scores on percutaneous nephrolithotomy outcomes. Urol Int. 2012; 89:301-6.
10. Nouralizadeh A1, Lashay A, Ziaee SA, et al. Percutaneous nephrolithotomy in high-risk patients: a single-center experience with more than 350 cases Urol Int. 2013; 90:394-8.

11. Ozturk E, Yilmazlar T. Factors affecting the mortality risk in elderly patients undergoing surgery. ANZ J Surg. 2007; 77:156-159.

12. Froehner M, Koch R, Litz R, et al. Comparison of the American Society of Anesthesiologists physical status classification with the Charlson score as predictors of survival after radical prostatectomy. Urology. 2003; 62:698-701.

13. Kuzgunbay B, Turunc T, Yaycioglu O, et al. Percutaneous nephrolithotomy for staghorn kidney stones in elderly patients. Int Urol Nephrol 2011; 43:639-643.

14. Gentle DL, Stoller ML, Bruce JE, et al. Geriatric urolithiasis. J Urol. 1997; 158:2221-2224.

15. Tonner PH, Kampen J, Scholz J. Pathophysiological changes in the elderly. Best Pract Res Clin Anaesthesiol. 2003; 17:163-177.

16. Akman T, Binbay M, Ugurlu M, et al. Outcomes of retrograde intrarenal surgery compared with percutaneous nephrolithotomy in elderly patients with moderate-size kidney stones: a matched-pair analysis J Endourol. 2012; 26:625-9.

17. De la Rosette J, Assimos D, Desai M, et al. CROES PCNL Study Group: The Clinical Research Office of the Endourological Society Percutaneous Nephrolithotomy Global Study: indications, complications, and outcomes in 5,803 patients. J Endourol. 2011; 25:11-17.

18. Kumar R, Anand A, Saxena V, et al. Safety and efficacy of PCNL for management of staghorn calculi in pediatric patients. J Pediatr Urol. 2011; 7:248-251.

19. Seitz C, Desai M, Häcker A, et al. Incidence, prevention, and management of complications following percutaneous nephrolitholapaxy. Eur Urol. 2012; 61:146.

20. Tefekli A, Karadag M, Tepeler K, et al. Classification of percutaneous nephrolithotomy complications using the modified Clavien grading system: looking for a standard. Eur Urol. 2008; 53:184.

21. Resorlu B, Diri A, Atmaca AF, et al. Can we avoid percutaneous nephrolithotomy in high-risk elderly patients using the Charlson Comorbidity Index? Urology. 2012; 79:1042-1047.

\section{Correspondence}

Erdem Kisa, MD

drerdemkisa@hotmail.com

Cem Yücel, MD

Murat Ucar, MD

drmuratucar@hotmail.com

Mehmet Zeynel Keskin. MD

zeynel_akd@hotmail.com

Ozgur Cakmak, MD

drozgurcakmak577@yahoo.com

Gokhan Koc, MD

gokfekoc@gmail.com

Zafer Kozacioglu, MD

zaferkozacioglu@gmail.com

Tepecik Training and Research Hospital, Urology Department, Izmir, Turkey

Salih Budak, MD

salihbudak1977@gmail.com

Sakarya Training and Research Hospital, Turkey 